\title{
Clinical profile of dengue hemorrhagic fever cases in Mexico
}

Joel N avarrete-Espinosa, MD, ${ }^{(1)}$ Héctor Gómez-D antés, MD, ${ }^{(2)}$ Juan Germán C elis-Q uintal, MD, ${ }^{(2)}$ José Luis Vázquez-Martínez, MD.(2)

\section{Navarrete-Espinosa J, Gómez-Dantés H, Celis-Quintal JG,Vázquez-Martínez JL. Clinical profile of dengue hemorrhagic fever cases in Mexico. Salud Publica Mex 2005;47:193-200.}

\begin{abstract}
A bstract
Objective. Dengue hemorrhagic fever is a public health problem in Mexico since 1994.W ith four serotypes circulating the risk of epidemic dengue hemorrhagic fever is increasing. Material and Methods. We describe the clinical features of confirmed cases in the social security health system (IMSS) from 1995 to 2003. Clinical picture and epidemiological features were compared and a multivariate model was fitted to evaluate associations. Results. Cases were divided into two groups: 438 patients with dengue fever, including 109 cases with hemorrhagic manifestations without thrombocytopenia, and 977 cases with dengue hemorrhagic fever, including 79 deaths. The main risk factors asso ciated with mortality were hematemesis (RR 2.6; C I 95\% 1.4-4.6) and melena (RR 2.2; CI 95\% 1.2-3.7). Conclusions. 0 ur results characterize the clinical profile of dengue hemorrhagic fever cases in Mexico and identify prognostic factors to alert clinician for the prevention of a fatal evolution.
\end{abstract}

Key words: dengue; thrombocytopenia; Mexico

\author{
Navarrete-Espinosa J, Gómez-Dantés $H$, \\ Celis-Quintal JG,Vázquez-Martínez JL. \\ Aspectos clínicos de los casos de fiebre hemorrágica \\ por Dengue en México. \\ Salud Publica Mex 2005;47:193-200.
}

\section{Resumen}

Objetivo. El dengue hemorrágico en México es una enfermedad emergente desde 1994. La circulación de los cuatro serotipos incrementa el riesgo de epidemias de dengue hemorrágico. Material y métodos. Se reportan los datos clínicos y epidemiológicos de los casos de dengue hemorrágico confirmados y notificados por el IMSS de 1995 a 2003. Se analizaron las características clínicas y epidemiológicas entre grupos. Para el control y la evaluación final de las variables se utilizó un modelo multivariado. Resultados. Los casos fueron asignados en dos grupos: 438 con dengue clásico, que incluye 109 casos con manifestaciones hemorrágicas sin trombocitopenia, y 977 casos de dengue hemorrágico con 79 defunciones. Los factores de riesgo asociados a las defunciones fueron: hematemesis (RR 2.6; IC 95\% 1.4-4.6) y melena (RR 2.2; IC 95\% 1.2-3.7). Conclusiones. El cuadro clínico descrito para la población del Instituto Mexicano del Seguro Social permite identificar factores pronósticos que ayuden al clínico a prevenir y manejar adecuadamente los casos severos de dengue hemorrágico.

Palabras clave: dengue; trombocitopenia; México

(1) Coordinación de los Programas Integrados de Salud (Unidad de Salud Pública, Instituto Mexicano del Seguro Social [IMSS]).

(2) División Técnica en Estadísticas de Salud, IMSS. 
D engue fever is an acute febrile viral disease characterized by headaches, joint and muscular pains, rash and leukopenia. Dengue Hemorrhagic Fever (DHF) has major clinical signs: high fever, hemorrhagic phenomena, often with hepatomegaly. In severe cases, called Dengue Shock Syndrome (DSS), patients may also develop hypovolemic shock resulting from plasma leakage. Dengue fever is the most significant arthropod-borne viral disease worldwide; it occurs in over 100 countries and territories and threatens the health of over 2500 million people in tropical and subtropical regions. Annually, it is estimated that there are 50-100 million cases of dengue infection and several hundred thousand cases of severe dengue worldwide, resulting in thousands of deaths. ${ }^{1,2}$ During 2002, more than 200 countries notified over 100000 cases of classical dengue and 17000 of DHF including 225 deaths. ${ }^{3}$ From 1979 to 2002, the Mexican Institute of Social Security (IMSS) reported 326959 Dengue cases, while the report of 2624 DHF cases started since 1995. ${ }^{4}$

The social determinants for the emergence of DHF in the Americas, as well as in Mexico, involve population growth, the rapid urbanization process along with the slower provision of public services as potable water, sewage, and garbage collection systems, especially in suburban settings. Water storage practices and disposable water containers in suburban neighborhoods have created a wide spectrum of breeding sites that favor mosquito densities in highly crowded areas. Dengue virus's transmission has also increased due to the growing transport capacity and migration movements from endemic areas. ${ }^{5,6}$

The biological risk factors associated with the development of DHF are the geographical origin of the viral strain, especially DEN-2, the presence of enhancing antibodies originated in the primary infection, the age, sex, race, nutritional status, host health conditions as well as the vector's competence and density. ${ }^{7}$

The control and surveillance activities established to face this emerging epidemic include the opportune diagnosis and treatment of severe dengue infection by physicians in public and private health institutions. Any case of DHF must be immediately notified to the national surveillance system and an epidemiological case study should be performed to confirm every suspected case. The confirmation of DHF cases is not an easy diagnosis due to the wide spectrum of signs and symptoms, the rapid progression of distinguished signs like thrombocytopenia and hemoconcentration, the common expectation to see severe hemorrhages, and the lack of serological diagnostic techniques at the local level. The recent emergence of DHF in Mexico and the low number of cases have also limited the practical experience of Mexican physicians in the diagnosis of this new clinical entity. Additionally, the diagnosis and acute evolution of DHF cases in the medical units requires efficient laboratory support to monitor the clinical evolution of the patient, which is not always available in endemic areas. The findings of this study aim to support the clinical diagnosis of DHF in Mexico and provide predictive factors of severe dengue infection that enable a better clinical management in the hospital units.

\section{Material and Methods}

A follow-up study was designed and conducted by health personnel in the IMSS to describe the clinical behavior of Dengue Fever (DF) and DHF and to determine some of the risk factors associated with the occurrence of hemorrhagic forms and fatal cases in the population attended by the most important social security system in Mexico. Patients were cases diagnosed as DF or DHF that were confirmed by a serological test (IgM-ELISA), notified to the Coordination of Health Integrated Programs of IMSS from 1995 to 2003. Clinical and epidemiological data were obtained from the case report format used by the national surveillance system to notify DHF cases. Cases reported in this study include only those that had all epidemiological, clinical information, and laboratory data available. The database included age, sex, time of onset, travel history, and contact with similar cases in the household or in the community. It also included clinical features like fever, hepatomegaly, bleeding signs, data for previous infection, the final outcome of the disease and laboratory results (hemoglobin, hematocrit and platelets). Two groups were formed according to their clinical evolution and following the WHO/PAHO established criteria: ${ }^{8}$ the DF and the Dengue Fever with Hemorrhagic Manifestations (DFHM) cases were included in the first group while the DHF cases, including fatal cases (FC), formed the second group. The fatal cases were patients that presented DSS as the main cause of death. Groups were compared according to their clinical evolution particularly during the acute phase of the disease.

Blood samples $(5 \mathrm{ml})$ were collected from each patient after the acute phase (5-8 days) in order to perform the serological diagnosis of dengue infection. Sera were obtained after centrifugation at $240(\mathrm{x} \mathrm{g})$ and 1500 rpm and were stored at -20 C. Rapid inmunochromatographic test (PanBio) $)^{9,10}$ was used according to the manufacturer procedures (sensitivity $94 \%$ and specificity $100 \%$ ). Dengue serological diagnosis was performed by the state public health laboratories (validated by 
Mexico's National Diagnostic and Reference Laboratory, INDRE) and the result was registered in the case surveillance format. Patients without serological diagnosis were excluded from the sample and this mainly occurred in those classified as dengue fever. Dengue virus isolation was performed when blood sample was taken in the early stages of the disease and sent to the INDRE in Mexico City.

The database was validated and analyzed to calculate simple frequencies, central tendency and dispersion measures. Cumulative incidence and relative risk were estimated along with their $95 \%$ confidence intervals (CI 95\%). The case fatality rate for DHF cases was also calculated. The statistical analysis to compare groups was performed using the Kruskal-Wallis test and Poisson regression. The analysis was run in STATA-V8.

\section{Results}

From January 1995 to June 2003, the IMSS notified a total of 2743 cases of DHF. We analyzed 977 cases of DHF (including 79 deaths), and 438 patients with dengue fever (including 109 DFHM cases), for a total of 1 415 individuals from 21 administrative regions or delegations (Table I). The highest number of cases (717) was reported during 2002 and Nuevo León Delegation reported 305 cases, followed by Guerrero (252), Colima (128), Yucatán (127), Veracruz (104), Sonora (103), Oaxaca (88), Sinaloa (53), Tamaulipas (57) and Chiapas (49). Although laboratory facilities are not widely distributed in the IMSS, $98 \%$ of the total cases included in this study were confirmed by determination of antibodies (ELISA-IgM) and dengue virus isolation was present in the rest of the patients. Dengue virus 1 (DEN-1) was isolated in three cases, DEN-2 in 19 patients and DEN-3 in 10 individuals.

Sex and mean age distribution were similar in all groups except in the fatal cases group where men predominated (62\%) and this group was significantly older (36.8 years) than the less severe cases. Previous personal experience of dengue infection was reported in similarly low proportions that increased when cases in the family were reported. Transmission of dengue in the community was reported by a vast majority of patients, especially by those with severe dengue (Table I).

General symptoms as fever, headache, myalgias and arthralgias, were present in similar proportion in each group. Exanthema, ocular pain, conjunctivitis and photophobia were more frequent in the DFHM group. On the other hand, a higher proportion of digestive
Table I

\section{Clinical profile of dengue: main signs and SYMPTOMS (\%). IMSS, MÉXICO, 1995-2003}

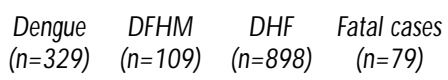

\begin{tabular}{lllll} 
Men & 48 & 45 & 50 & 62 \\
\hline Women & 52 & 55 & 50 & 38 \\
\hline Mean age (yrs.) & 28.1 & 26.1 & 26.9 & 36.8 \\
\hline Previous dengue infection & 13 & 13 & 16 & 11 \\
\hline Cases in family & 29 & 33 & 29 & 24 \\
\hline Cases in community & 70 & 72 & 81 & 78 \\
\hline Fever & 97 & 99 & 99 & 98 \\
\hline Headache & 91 & 94 & 90 & 90 \\
\hline Myalgias & 90 & 90 & 88 & 89 \\
\hline Arthralgias & 80 & 80 & 85 & 85 \\
\hline O cular pain & 72 & 89 & 70 & 56 \\
\hline Exanthema & 36 & 56 & 41 & 29 \\
\hline Conjunctivitis & 35 & 50 & 36 & 18 \\
\hline Photophobia & 37 & 55 & 41 & 22 \\
\hline N ausea & 56 & 77 & 71 & 49 \\
\hline Vomit & 34 & 52 & 60 & 47 \\
\hline Abdominal pain & 36 & 52 & 59 & 55 \\
\hline Hepatomegaly & 4 & 10 & 12 & 22 \\
\hline Splenomegaly & 3 & 6 & 4 & 6
\end{tabular}

DFHM: dengue fever with hemorrhagic manifestations DHF: dengue hemorrhagic fever

symptoms such as vomit and abdominal pain were found in the DHF and fatal cases. Hepatomegaly was mainly documented in the fatal cases group (Table I).

Higher frequencies of weak capillary and plasma leakage signs were reported in fatal cases $(83 \%)$ compared with DHF (61\%) and DFHM (72\%) groups. Echymosis, hematomas, ascitis and pleural effusion were the more prominent signs reported in the fatal cases group. On the other hand, a positive tourniquet test was higher in the less severe cases. Hemorrhagic manifestations were recorded in $41 \%, 49 \%$ and $93 \%$ of patients in each group. Spontaneous bleeding signs like gingival bleeding and epistaxis were higher in the DHF group but severe hemorrhages like melena and hematemesis appeared distinctively in the fatal cases. Simultaneous plasma leakage and hemorrhagic signs were present in $16 \%$ of the DFHM cases and 30\% of DHF cases but occurred in almost every fatal case (79\%). These findings are paralleled by the mean values for hemoglobin, hematocrit, and platelets, that were the lowest in fatal cases. The average number of days between the 
onset of signs and symptoms to the onset of spontaneous bleeding or plasma leakage signs was significantly higher $(p<0.05)$ for DHF and fatal cases (Table II).

Thrombocytopenia ( $<100000$ platelets) was initially detected in the first blood sample in $82 \%$ of DHF patients $(87 \%$ in FC) and this hematological dysfunction was confirmed in subsequent blood samples for the rest of the cases. Graphical view of platelet counts showed that the median number of platelets was significantly lower in fatal cases and the recuperation trend was faster in less severe cases (DHF) (Figure 1). Hemoconcentration (hematocrit/hemoglobin ratio $>3.3$ ) was documented in $8 \%$ of the DHF cases and $34 \%$ of FC with a first sample. Both hemoconcentration and thrombocytopenia were found in $6 \%$ of DHF and $25 \%$ of FC. Plasma leakage and thrombocytopenia were present together in $51 \%$ of DHF cases (71\% in FC). On the other hand, spontaneous bleeding and thrombocytopenia occurred simultaneously in $41 \%$ of DHF cases ( $84 \%$ in FC); while, plasma leakage and hemoconcentration were present in $5 \%$ (22\% in deaths) and spontaneous bleeding and hemoconcentration were present in 3\% (24\% in deaths).

Some of the most prominent signs of severity of the infection, abdominal pain and hepatomegaly, along with petechia, gingival bleeding and epistaxis were associated with an increased risk for the occurrence of DHF. In the multivariate analysis the risk factors that appeared predictive of severity and indicated a major risk for death were: echymosis (RR 2.8; CI 95\% 1.6-4.9), hematomas (RR 2.6; CI 95\% 1.3-5.2), ascitis (RR 3.1; CI 95\% 1.4-6.6), hematemesis and melena (RR. 3.1; CI 95\% 1.9-5.1) (Table III). According to the number of leakage and bleedings signs, we found that patients with two or more signs showed an increased risk to develop DHF. The simultaneous presence of plasma leakage and spontaneous bleedings resulted in an increased risk of 2.6 (CI 95\% 2.1-3.1) for the occurrence of DHF compared with those who did not.

Evolution of clinical features for fatal cases had a mean duration of $7.8(S D=5.4)$ days from the beginning of the disease until death (median=7). Also, the

\section{Clinical profile of seVere dengue. Hemorrhagic signs and parameters. IMSS, México, 1995-2003}

Clinical parameters

Petechia

Echymosis

Hematomas

Tourniquet test ( + )

Gingival

Epistaxis

Hematemesis

Melena

Ascites

Pleural effusion

\begin{tabular}{lc} 
& $(n=104)$ \\
\hline Hemoglobin & $12.9 \pm 1.8$ \\
& $(n=103)$ \\
\hline Hematocrit * & $39.3 \pm 5.5$ \\
& $(n=96)$
\end{tabular}

Mean days for spontaneous bleeding

Mean days for plasma leakage

* percent

₹ grs. $\mid 100 \mathrm{ml}$

$\S(x$ 1000)

DFHM: dengue fever with hemorrhagic manifestations DHF: dengue hemorrhagic fever

$$
\begin{aligned}
& \text { Dengue } \\
& (n=329)
\end{aligned}
$$

DFHM

$(n=109)$

$$
\underset{(n=898)}{\mathrm{DHF}}
$$

Fatal cases $(n=79)$

$62 \quad 63$

$\begin{array}{lll}10 & 17 & 39\end{array}$

$\begin{array}{ll}7 & 7\end{array}$

$46 \quad 45$

17

21

2

8

- 4

$-$

$\begin{array}{lr}92.5 \pm 76.1 & 69.8 \pm 62 \\ (\mathrm{n}=81) & (\mathrm{n}=87 .\end{array}$

$13.6 \pm 2.0$
$(n=81)$

$\begin{array}{ccc}(n=81) & (n=803) & (n=50) \\ 40.2 \pm 3.7 & 41.1 \pm 6.2 & 32.3 \pm 9.9 \\ (n=67) & (n=753) & (n=44)\end{array}$

$\begin{array}{ccc}(n=67) & (n=753) & (n=44) \\ 2.8 & 3.7 & 3.9\end{array}$

$\begin{array}{lll}2.8 & 3.7 & 3.9 \\ 2.6 & 3.5 & 3.3\end{array}$




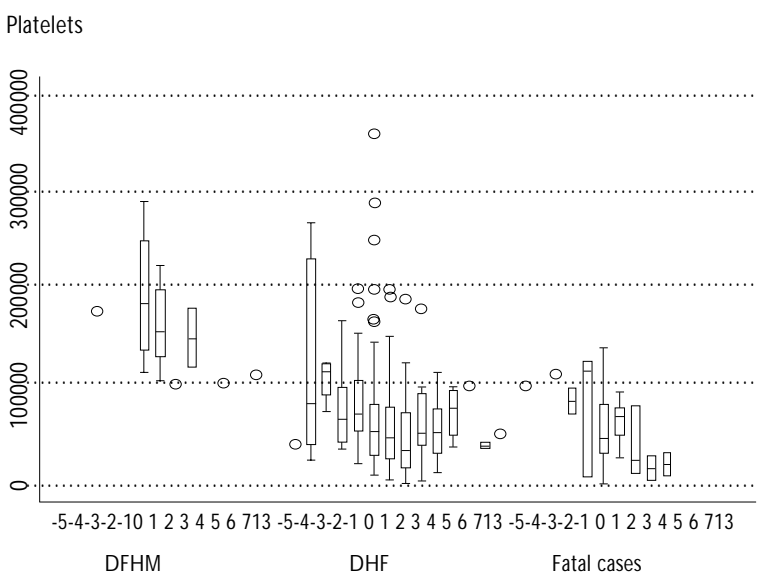

Day $0=$ onset of hemorrhagic manifestations

Figure 1. Platelets levels by days of hemorrhagic MANIFESTATIONS IN DENGUE CASES ACCORDING TO SEVERIty OF INFECTION. IMSS, MÉXICO, 1995-2003

Table III

RISK FACTORS ASSOCIATED WITH SEVERE DENGUE INFECTION. MÉXICO, 1995-2003

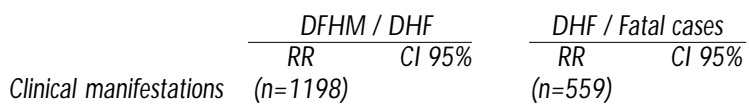

\begin{tabular}{lllll} 
Abdominal pain & 1.3 & $1.2-1.4$ & & \\
\hline Hepatomegaly & 1.2 & $1.1-1.4$ & & \\
\hline Petechia & $2.5^{*}$ & $2.2-2.9$ & & \\
\hline Echymosis & 1.6 & $1.4-1.7$ & 2.8 & $1.6-4.9$ \\
\hline Hematomas & & & 2.6 & $1.3-5.2$ \\
\hline Pleural effusion & 1.6 & $1.5-1.7$ & & \\
\hline Ascitis & $1.6^{*}$ & $1.5-1.7$ & 3.1 & $1.4-6.6$ \\
\hline Gingival bleeding & 1.9 & $1.7-2.0$ & & \\
\hline Epistaxis & $1.8^{*}$ & $1.7-2.0$ & & \\
\hline Hematemesis & 1.8 & $1.7-1.9$ & $3.1^{*}$ & $1.9-5.2$ \\
\hline Melena & & & $3.1^{*}$ & $1.9-5.1$
\end{tabular}

* remaining factors in the multivariate model

DFHM: dengue fever with hemorrhagic manifestations DHF: dengue hemorrhagic fever

average time from the start of the illness to the appearance of plasma leakage or hemorrhages was 3.3 $(S D=3.5)$ days (median=2) and $3.9(S D=4.1)$ days (median=3) respectively; and $4.8(S D=5.6)$ days (median $=4)$ and $4.1(S D=5.5)$ days (median=3), from the beginning of the plasma leakage and spontaneous hemorrhages to death.

\section{Discussion}

The wide variety of signs and symptoms associated with severe dengue infection and the identification of those that are required to distinguish and classify DHF from DSS cases is a major clinical challenge that demands laboratory support and a detailed clinical monitoring of blood pressure, pulse, temperature, urinary output, hematocrit and platelet counts. Clinical studies differed in the spectrum of signs and symptoms reported and usually emphasized those that are more prominent in the population studied (Table IV).

The clinical reports of DHF in Southeast Asia are focused in children under 15 years of age, the age group most affected by dengue virus infection. The situation in the Americas reflects that DHF is more prevalent in the young and adult population; therefore, it is necessary to highlight their clinical profile and the findings reported in this study provide meaningful clinical features to improve its diagnosis and management in the Latin American context. ${ }^{11}$

The reported frequency of the general signs and symptoms -fever, malaise, headache, retro orbital pain, mialgias and arthralgias, exanthema-in different populations is certainly due to the accuracy of the clinical history and the clinical stage of the disease. In children, dengue-like symptoms may not be as pronounced as in adults, in whom benign dengue fever syndrome is classically seen. Dengue in children is often misdiagnosed as an undifferentiated fever or other viral diseases like measles, rubella, ${ }^{12}$ and in adults with leptospirosis ${ }^{13}$ or rickettsiosis. ${ }^{14}$ Exanthema is a prominent clinical sign and its report varied from 3\% to $53 \%$ in the series of severe dengue cases. ${ }^{15,16}$

Nevertheless, the most prominent features necessary to confirm DHF require a detailed discussion. The positive tourniquet test is more frequently reported in the Asian countries ${ }^{17-19}$ and varies from $2-31 \%$ in Puerto Rico ${ }^{16,20}$ to $81-84 \%$ in Thailand. ${ }^{17}$ The problems associated with its practical use in all patients and the low sensitivity of the interpretation of the test should alert clinicians about its small predictive value to distinguish dengue hemorrhagic cases. The presence of more than one plasma leakage or hemorrhagic manifestations in a patient provides a more conclusive criterion to distinguish clinical severity. Minor hemorrhages like petechia, gingival bleeding and epistaxis are more common than gastrointestinal bleeding -hematemesis and melena- or hematuria, but these are important hemorrhagic signs that demand examination. Gastroin- 
Table IV

\section{Clinical manifestations of dengue hemorrhagic fever (DHF) in Selected countries. México, 1995-2003}

\begin{tabular}{|c|c|c|c|c|c|c|c|c|c|}
\hline & $\begin{array}{l}\text { Thailand } \\
(17,22,23)\end{array}$ & $\begin{array}{l}\text { Cuba } \\
(25-27)\end{array}$ & Philippines & $\begin{array}{l}\text { China } \\
(15,19)\end{array}$ & $\begin{array}{l}\text { Puerto Rico } \\
(16-20)\end{array}$ & $\begin{array}{l}\text { Delhi } \\
\text { (24) }\end{array}$ & $\underset{(32)}{\text { French Guyana }}$ & $\underset{(29)}{N}$ & $\begin{array}{c}\text { Cuba } \\
\text { (28) }\end{array}$ \\
\hline Signs and Symptoms \% & 1958-65* & $1981^{\ddagger}$ & $1984^{\ddagger}$ & $1985^{\ddagger}$ & $1990-91^{\ddagger}$ & $1988 *$ & $91-92^{\ddagger}$ & $1994^{\ddagger}$ & $1997^{\ddagger}$ \\
\hline Fever & 100 & 97 & 81 & 100 & $88-100$ & 100 & 100 & 100 & 100 \\
\hline Headache & 44 & 77 & - & 86 & 78 & - & 78 & 100 & 91 \\
\hline Myalgias & $10-12$ & 44 & 32 & 100 & 77 & - & 60 & 100 & 75 \\
\hline Arthralgias & 12 & 54 & 12 & 100 & 64 & - & 65 & 100 & - \\
\hline 0 cular pain & - & 19 & 4 & - & 63 & - & - & - & - \\
\hline Conjunctivitis & 33 & - & 10 & 3 & - & - & - & - & - \\
\hline Exanthema & $10-13$ & 13 & - & 3 & $47-53$ & - & - & - & - \\
\hline Cough & $21-40$ & - & 21 & - & 35 & - & - & - & - \\
\hline $\mathrm{N}$ asal congestion & 13 & - & 7 & - & 29 & - & - & - & - \\
\hline $\mathrm{N}$ ausea & 70 & 71 & 30 & 96 & 53 & - & 75 & - & - \\
\hline Vomit & $58-70$ & $71-87$ & 33 & 62 & 53 & 86 & 63 & - & 38 \\
\hline Diarrhea & $6-13$ & 14 & 3 & - & 30 & - & - & - & - \\
\hline Abdominal pain & $25-50$ & $23-63$ & 42 & 83 & - & 52 & 60 & 62 & 86 \\
\hline Hepatomegaly & $45-90$ & $11-67$ & 14 & 5 & 11 & 71 & - & - & 51 \\
\hline Splenomegaly & 6 & - & - & - & & 24 & - & - & - \\
\hline Ascites, edema & - & $8-31$ & - & - & 5 & 100 & 10 & - & 69 \\
\hline Pleural effusion & 25 & 8- 56 & - & 1 & - & 91 & 10 & - & 30 \\
\hline Petechia & $46-62$ & 50 & 64 & 27 & $16-46$ & 100 & - & 12 & - \\
\hline Echymosis & - & 7- 55 & 13 & 27 & 17 & 100 & - & - & - \\
\hline Hematomas & - & - & - & 27 & 17 & - & 18 & - & - \\
\hline Tourniquet + & $81-84$ & - & 70 & 67 & $2-31$ & - & - & 25 & - \\
\hline Gingival & - & 14 & 7 & 18 & 14 & - & 25 & - & - \\
\hline Epistaxis & $10-19$ & $9-11$ & 45 & 36 & $3-23$ & - & 20 & 38 & - \\
\hline Hematemesis & $12-22$ & $14-30$ & 7 & 27 & $2-7$ & - & 25 & 12 & - \\
\hline Melena & $12-15$ & $5-8$ & 10 & 8 & $2-14$ & 14 & 15 & - & - \\
\hline Thrombocytopenia & 100 & $78-80$ & 72 & 79 & 100 & 86 & - & 100 & 99 \\
\hline Hemoconcentration & 100 & $34-83$ & 39 & 40 & 59 & 86 & - & 100 & 100 \\
\hline Lab. confirmed & - & 100 & 49 & 70 & 26 & 71 & 65 & - & - \\
\hline Hospitalized & - & - & - & 100 & 16 & 100 & - & - & 79 \\
\hline Shock signs & 35 & - & - & 14 & 5 & 95 & 20 & 25 & 15 \\
\hline Case fatality & - & 1.5 & 0 & 0.25 & 5.2 & 33 & 15 & - & 5,8 \\
\hline
\end{tabular}

* Pediatric patients

₹ Adults and pediatric patients

() References

testinal bleeding may initially be hidden and usually manifests as an abdominal pain or tenderness, a distended abdomen, pallor, tachycardia, or a drop in hematocrit without clinical improvement. ${ }^{21}$ Hematuria may also be hidden (microhematuria) and only perceived by urine analysis, which should be routinely performed in every suspected case. Report of dengue hemorrhagic cases in the IMSS demonstrated that severe dengue infection is usually accompanied by more than one bleeding site $(30 \%)$ and that gastrointestinal bleeding as well as petechia and epistaxis were prominent signs. The first epidemic of DHF in China also resulted in $60 \%$ of DHF cases with two or more hemorrhagic manifestations. ${ }^{15}$

Based on the Thai experience, exploration of the hepatic area should also be emphasized since the frequency of hepatomegaly is below that reported in Thai populations $(45-90 \%)^{17,22,23}$ and in India $\left.(71 \%)\right)^{24}$ The 
prevalence could be higher due to the readiness to detect hepatomegaly in children more than in adult populations. DSS reported higher prevalence of hepatomegaly $(16 \%$ in adults and $60 \%$ in children) than DHF ( $7 \%$ in adults and $22 \%$ in children) as was also found in children and adults with severe and fatal dengue in Cuba. ${ }^{25-27}$ Abdominal pain, nausea and vomit are among the alarm signs -digestive syndrome- that revealed the imminent evolution towards severity and these features were differentially reported in DHF cases compared to DF cases in the IMSS. Abdominal pain -alarm sign that may predict gastrointestinal bleeding-is also among the symptoms more frequently reported in different case series ranging from 23 to $86 \%{ }^{26,28}$

The hematological parameters like thrombocytopenia and hemoconcentration -essential to confirm DHF- defy the laboratory infrastructure in medical units in many developing countries. The studies that report $100 \%{ }^{29}$ of cases with thrombocytopenia reflect the strict compliance with $\mathrm{WHO}$ guidelines as well as the challenge to meet by other developing countries that lack the laboratory resources to study all suspected cases. The criteria for hemoconcentration is difficult to satisfy either because of hemodynamic changes produced by early treatment with intravenous solutions, the severity of the disease, or even the death of the patient. This issue becomes relevant when the prognosis of DHF is highly dependent on the evolution of these two parameters. A severe thrombocytopenia of less than 50000 per cubic millimeter was found in $74 \%$ of fatal cases in Thailand. ${ }^{22}$ The significant differences found in the mean values of platelets and hematocrit in fatal versus convalescent patient's supports those findings in Thailand and provide vital clinical information for the opportune detection and treatment of severe cases. The continuous monitoring of thrombocytopenia and hemoconcentration should be viewed as an obligatory procedure and not only as a diagnostic criterion. Based on the results reported, only $94 \%$ of the 977 patients with DHF had platelet counts performed for their initial diagnosis of whom $82 \%$ had less than $100000 \mathrm{~m}^{3}$. Second samples were taken in $65 \%$ of the patients and a third sample decreased to $39 \%$ of the patients. Serial samples were used to finally confirme thrombocytopenia in all 977 patients. Initial blood samples to test for hemoconcentration were performed in $82 \%$ of all patients. All had decreasing numbers on the sequential samples taken, minimizing the analytical potential of such clinical data. For example, although 109 cases of DF had plasma leakage or bleeding, only $74 \%$ of them had a first blood sample to detect thrombocytopenia or hemoconcentration; $42 \%$ and $31 \%$ had a second and third sample, respectively. The study of cases was incomplete; therefore, they were only classified like dengue with hemorrhagic manifestations. These operational obstacles compelled the local health personnel to diagnose and confirm DHF cases based on limited clinical information and use the epidemiological criteria to establish the final diagnosis.

Thrombocytopenia was present in $100 \%$ of the notified cases, while hemoconcentration was documented in only $12 \%$ of them. An important finding is the proportion in which both events are registered simultaneously and the risk to develop hemorrhagic Dengue and death from this cause. Also, the relationship found between plasma leakage and spontaneous bleedings with hemoconcentration and thrombocytopenia has important implications to determine prognostic factors for the clinical evolution that would allow establishing a timely monitoring and appropriate treatment for ill persons.

The operational case definition of DHF establishes that the patient must show clinical manifestations of plasma leakage or spontaneous bleedings besides thrombocytopenia and hemoconcentration. However, it is important to take into account timing and sequence of these events, because the mentioned parameters are not present in all cases simultaneously. In this relationship it should be considered that theoretically, thrombocytopenia determines the onset of spontaneous bleedings and it must precede them or coincide with time of onset. In contrast, the beginning of plasma leakage and volume depletion determines the presence of hemoconcentration; therefore, the leakage precedes it. Then, the frequency of these parameters depends on the form corporal fluids are lost during the infection, hemorrhages or plasma leakage, and time in which laboratory tests are requested. These parameters have been useful to establish operational criteria to classify cases; ${ }^{8}$ nevertheless, findings of this study invite us to design operative research to understand the clinical behavior of the disease and to establish appropriate criteria to confirm cases, properly classify the severity of the disease and estimate its real occurrence. ${ }^{30}$

Laboratory diagnosis is an issue of serious concern in all endemic countries. Approximately $45 \%$ of all notified cases at the IMSS are laboratory confirmed. This rate is low, although rates in other countries are rarely near 100\%. This issue becomes relevant because delay in diagnosis may well affect the prompt treatment required to save the patient from a severe dengue infection and death. Experience from 12 Asian countries demonstrated that DHF-DSS case fatality rates vary between $0.5 \%$ and $3.5 .{ }^{31}$ Global case fatality rate in the IMSS $(2.9 \%)$ is smaller than that reported in Cuba (5.8\% in 1997), Puerto Rico (5.2\% in 1991), the 
French Guyana (15\% in 1991), ${ }^{32}$ and India (33\% in 1988). Prompt clinical and laboratory support is essential to reduce the risk of death and provides adequate information to monitor the severity of the disease. Data provided by studies like this should help the physicians and the public health service to improve the dengue surveillance system and the prevention of this emergent infectious disease.

\section{References}

1. Jacobs M. D engue: Emergence as a global public health problem and prospects for control.Trans Royal Soc Trop Med Hyg 2000;94:7-8. 2.W orld Health $O$ rganization. Report on global surveillance of epidemic-prone infectious diseases. W HO /CDS/C SR/ISR/2000.1 3. G uzmán MG , Kourí G. D engue and dengue hemorrhagic fever in the Americas: lessons and challenges.J C lin Virol 2003;27(1):1-13. 4. Boletines Epidemiológicos 1979-2002. Coordinación de Salud Pública. Instituto Mexicano del Seguro Social.

5. N arro-Robles J, Gómez-D antés H. El dengue en México: un problema prioritario de salud pública. Salud Publica Mex 1995;37 supl:S12-S20.

6. Guzmán MG , Kourí G. Dengue:An update. Lancet Infect $D$ is 2002;2(1):33-42.

7. Gubler DJ. D engue and dengue hemorrhagic fever. Clin Microbiol Rev 1998;11(3):480-496.

8.W orld H ealth 0 rganization. D engue haemorrhagic fever: D iagnosis, treatment, prevention and control. Geneva:W HO; 1997.

9. Cuzzubbo AJ,Vaughn DW, N isalak A, Solomon T, Kalayanarooj S, Aaskov J et al. Comparison of PanBio dengue duo enzyme-linked immunosorbent assay (ELISA) and MRL dengue fever virus immunoglobulin M capture ELISA for diagnosis of denguevirus infections in So utheast A sia. Clin Diagn Lab Immunol 1999;6(5):705-712.

10. Porter KR,W idjaja S, Lohita HD, Hadiwijaya SH, Maroef CN, Suharyono $\mathrm{W}$ et al. Evaluation of a commercially available immunoglobulin M capture enzyme-linked immunosorbent assay kit for diagnosing acute dengue infections. Clin Diagn Lab Immunol 1999;6(5):741-744. 11. Ramos C, García H,Villaseca JM. Fiebre hemorrágica y síndrome de choque por dengue. Salud Publica Mex 1993;35(1):39-55.

12. Bustos J, Hamdan A, Loroño MA. Serologically proven acute rubella infection in patients with clinical diagnosis of dengue. Epidemiol Infect 1990;104(2):297-302.

13. ZavalaVJ,Vado SI, Rodríguez FM, Rodríguez AE, Barrera PM, G uzmán $M E$. Leptospirosis anictérica en un brote epidémico de dengue en la Península de Yucatán. Rev Biomed 1998:9(2):78-83.

14. ZavalaVJ,Yu XJ, W alker DH. Unrecognized spotted fever group rickettsiosis masquerading as dengue fever in Mexico.Am JTrop Med Hyg 1996;55(2):157-159.
15. Q iu FX, Chen $Q Q, H o$ Q Y, Chen W Z, Zhao ZG, Zhao BW. The first epidemic of dengue hemorrhagic fever in the people's Republic of China.Am J Trop Med Hyg 1991;44(4):364-370.

16. Cobra C, Rigau-Pérez JG, Kuno G,Vorndam V. Symptoms of dengue fever in relation to host immunologic response and virus serotype, Puerto Rico, 1990-1991. Am J Epidemiol 1995;142(11):1204-1211. 17. Halstead SB. D engue and hemorrhagic fevers of southeast $A$ sia. The Yale Journal of Biology and Medicine 1965;37(6):434-454.

18. Hayes CG, Manaloto CR, G onzález A, Ranoa CP. D engue infections in the Philippines: clinical and virological findings in 517 hospitalized patients. Am J Trop Med Hyg 1988;39(1):110-116.

19. Q iu FX, Gubler DJ, Liu J Ch, Chen Q Q . Dengue in China:A clinical review. Bull W orld Health O rgan 1993;71(3/4):349-359.

20. Rigau-Pérez JG. C linical manifestations of dengue hemorrhagic fever in Puerto Rico, 1990-1991. Pan Am J Public Health 1997;1(5):381-388.

21. George R, Lum L. C linical spectrum of dengue infection. En: Gubler $D J$, Kuno $G$. Dengue and dengue hemorrhagic fever.W allingford, UK: CAB International 1997:89-113.

22. N elson E, C hulajata R. D anger signs in Thai hemorrhagic fever (dengue).Tropical Pediatrics 1965;67(3):463-470.

23. N elson ER. Hemorrhagic fever in children in Thailand. Report of 69 cases. Tropical Pediatrics 1960;56(1):101-108.

24. Kabra SK, Verma IC, A rora N K, Jain Y, Kaira V. D engue hemorrhagic fever in children in Delhi. Bull World Health 0 rgan 1992;70(1):105-108. 25. G uzmán MG , Kourí GP, Martínez E, Bravo J, Rivero R, Soler M. $C$ linical and serologic study of $C$ uban children with dengue hemorrhagic/dengue shock syndrome (DHF/DSS). Bull Pan Am Health O rgan 1987;21(3):270-279.

26. Díaz A, Kourí GP, Guzmán MG , Lobaina L, Bravo J, Ruiz A et al. Cuadro clínico de la fiebre hemorrágica del dengue/ síndrome de choque del dengue en el adulto. Bol Of Sanit Panam 1988;104(6):560-571.

27. Kourí GP, G uzmán MG, Bravo JR, Triana C. Dengue hemorrhagic fever/ dengue shock syndrome: lessons from the Cuban epidemic, 1981. Bull World Health O rgan 1989;67(4):375-380.

28.Valdés L, G uzmán MG, Kourí GP, D elgado J, C arbonell I, C abrera MV et al. La epidemiología del dengue y el dengue hemorrágico en Santiago de Cuba, 1997. Rev Panam Salud Publica 1999;6(1):16-24.

29. Guzmán MG,Vázquez S, Martínez E,Alvarez M, Rodríguez R, Kourí G et al. Dengue en $\mathrm{N}$ icaragua, 1994: reintroducción del serotipo 3 en las A méricas. Bol 0 ficina Sanit Panam 1996;121(2):103-110.

30. Rigau-Pérez JG, Bonilla GL.An evaluation of modified case definitions for the detection of dengue hemorrhagic fever. Puerto Rico Association of Epidemiologists. P R Health Sci J 1999;18(4):347-352. 31. Halstead S. Is there an inapparent dengue explosion? Lancet 1999:353:1100.

32. Reynes JM, Laurent A, D eubel V, Telliam E, Moreau JP.The first epidemic of dengue hemorrhagic fever in French Guiana.Am J Trop Med Hyg 1994;51(5):545-553. 